\section{Antihistamines in Atopic Dermatitis Therapy}

\author{
Nikolay Potekaev ${ }^{1,2}$, Irina Khamaganova ${ }^{1 *}$ and Irina \\ Vorontsova ${ }^{1}$
}

${ }^{1}$ Department of Skin Diseases \& Cosmetology, Pirogov Russian National Medical University, Moscow, Russia

${ }^{2}$ Moscow Department of Health, Moscow, Russia

\begin{abstract}
Summary
The review of antihistamine therapy in atopic dermatitis is presented. Traditionally, antihistamines are being used to treat itching which is the crucial sign of atopic dermatitis with a major impact on health-related quality of life. Besides the antihistamine and anti-inflammatory effects of antihistamines, the sedative action of the treatment is rather useful. The scratching behavior in experimental animals is related with histamine $\mathrm{H}_{1}$. Topical usage of antihistamines was proved experimentally to be sensible. The next generation of antihistaminic agents possessing $\mathrm{H}_{1} R$ and $\mathrm{H}_{4} \mathrm{R}$ antagonistic actions is being examined now. However, there are certain opinions which concluded that there is no reliable high-level evidence to support or refute the efficacy or safety of oral $\mathrm{H}_{1}$ antihistamines used as monotherapy. Furthermore, it was emphasized that antihistamines have demonstrated poor efficacy in controlling atopic dermatitis-associated itch. The controversial points of view predispose to further investigations.
\end{abstract}

Keywords: Antihistamines; Atopic dermatitis

\section{Introduction}

Histamine is the best-known pruritogen and also acts as an experimental itch-causing substance. Pruritus is an essential feature of atopic dermatitis and one of the most debilitating symptoms with a high impact on the quality of life [1,2]. Although the pathophysiology of atopic dermatitis itch is not fully understood, recent studies have demonstrated that a variety of mechanisms contributed to the induction and maintenance of the symptom. For example, an increased number of cutaneous nerve fibers and neuropeptides were identified in atopic dermatitis skin. Histamine and histamine 4 receptor as well as interleukin 31 are the key players identified in itch induction [1].

Beyond dermatologic disorders, chronic pruritus is associated with systemic, neurologic as well as psychologic diseases [3-6]. In such

*Corresponding author: Irina Khamaganova, Department of Skin Diseases \& Cosmetology, Pirogov Russian National Research Medical University, Moscow, Russia, Tel: +7 9859984481; Fax: +7 495770095; E-mail: clinderm11@gmail.com

Citation: Potekaev N, Khamaganova I, Vorontsova I (2015) Antihistamines in Atopic Dermatitis Therapy. J Allergy Disord Ther 2: 003.

Received: February 17, 2015; Accepted: March 26, 2015; Published: April 10, 2015 cases we can see vicious circle formed by pruritus pathophysiology and neurologic or psychic disorders on the other hand.

Clinically, antihistamines, i.e., histamine $\mathrm{H}_{1}$-receptor blockers, are commonly used to treat all types of itching resulting from renal and liver diseases, as well as from serious skin diseases such as Atopic Dermatitis (AD) [7]. Antihistaminic drugs prescribed in AD may support the therapy of the itching skin disease. However, there are no controlled studies which show the efficacy of antihistaminic drugs on the skin condition in $\mathrm{AD}$.

Rossbach K et al., demonstrated that histamine induces a calcium increase in a subset of skin-specific sensory neurons via activation of the $\mathrm{H}_{1} \mathrm{R}$ and $\mathrm{H}_{4} \mathrm{R}$ as well as inhibition of the $\mathrm{H}_{3} \mathrm{R}$. The decreased threshold in response to $\mathrm{H}_{3} \mathrm{R}$ antagonism activated $\mathrm{H}_{1} \mathrm{R}$ and $\mathrm{H}_{4} \mathrm{R}$ on sensory neurons, which in turn resulted in the excitation of histamine-sensitive afferents and therefore elicited the sensation of itch [8].

We can find contradictory hypothesis about the feasibility of using antihistamines in $\mathrm{AD}$. $\mathrm{H}_{1}$-antihistamines, especially the sedating type, have been prescribed for a long time in $\mathrm{AD}$ in order to reduce pruritus, the crucial symptom with a major impact on health-related quality of life [9-11].

Church MK and Maurer M (2015), presented different points of view on this subject [12]. The sedating type of $\mathrm{H}_{1}$-antihistamines have long been prescribed in $\mathrm{AD}$ in an attempt to reduce pruritus. On the other hand, no randomised trials comparing an oral $\mathrm{H}_{1}$-antihistamine with placebo or control were presented [12].

The Cochrane systematic review concluded that there was no reliable high-level evidence to support or refute the efficacy or safety of oral $\mathrm{H}_{1}$ antihistamines used as monotherapy. Most of the studies allowed the use of concomitant medications and involved multi-therapeutic approaches. Meaningful assessments of the individual effects of oral $\mathrm{H}_{1}$ antihistamines on eczema were not feasible as far as most of the studies allowed the use of concomitant medications and involved multi-therapeutic approaches. Although well-designed randomised controlled trials excluding concomitant medications appear to be needed, consideration should be given to the potential ethical issues raised with the use of antihistamines as monotherapy for the management of eczema by withholding the use of rescue or additional therapies. A further systematic review of studies in which concomitant therapies were permitted might be of value in determining the potential benefits of oral $\mathrm{H}_{1}$ antihistamines as add-on therapy to support the use of these drugs in $\mathrm{AD}$, particularly as a monotherapy [13].

The objective of the review is to evaluate the full significance of antihistamines for atopic dermatitis.

\section{Material and Methods}

The main source of information was Medline Pubmed. We used the keywords "atopic dermatitis", "antihistamines", "priritus". The 104 publications since 2006 till 2015, January were analyzed. We selected 51 publications that presented the therapeutical efficacy, research performed on experimental animal models, side effects of anthistamines. 


\section{Experimental Research on Animal Models}

The certain experimental proof of the reasoning for using antihistamines in $\mathrm{AD}$ is obvious. Nakasone $\mathrm{T}$ et al., presented the investigation of scratching behavior in ADJM mice (Atopic Dermatitis from Japanese Mice) [14]. Histamine $\mathrm{H}_{1}$ antagonist, chlorpheniramine administered orally, inhibited this behavior potently and dose-dependently. Histamine $\mathrm{H}_{1}$ antagonist with serotonin 5-TH (5-Hydroxytryptamine) 2 antagonist, cyproheptadine, also inhibited this behavior. However, $\mathrm{NK}_{1}$ antagonist, aprepitant, administered orally, had no significant inhibitory effect even at a dose of $100 \mathrm{mg} / \mathrm{kg}$, administered orally. $\mathrm{Mu}$ antagonist, naloxone, and kappa agonist, nalfurafine, significantly inhibited this behavior at doses of $0.3 \mathrm{mg} / \mathrm{kg}$, subcutaneously, and $0.01 \mathrm{mg} / \mathrm{kg}$, administered orally, respectively. Histamine contents in the skin of ADJM mice were significantly higher than in other mice. These results obtained by Nakasone T et al., strongly indicate that scratching behavior in ADJM mice was related with histamine $\mathrm{H}_{1}$, opioid $\mu$ and opioid $\kappa$ receptors.

Unlike other $\mathrm{H}_{1}$ antihistamines, azelastine decreased lipopolysaccharide-induced tumor necrosis factor $a$ and interleukin-12 secretion from murine bone marrow-derived DC. This effect was independent of histamine receptors $\mathrm{H}_{1}, \mathrm{H}_{2}$, or $\mathrm{H}_{4}$ and may be linked to inhibition of the nuclear factor kappa $\mathrm{B}$ pathway. Only azelastine reduced proliferation of allogenic $\mathrm{T}$ cells in a mixed leukocyte reaction. Schumacher S et al., tested topical application of the $\mathrm{H}_{1}$ antihistamines on mice sensitized against toluene-2,4-diisocyanate, a model of Th2-mediated allergic contact dermatitis. In contrast to the in vitro results, all investigated substances were efficacious in reducing allergic ear swelling. Azelastine has unique effects on dendritic cells and $\mathrm{T}$ cell interaction in vitro. However, this did not translate into superior in vivo efficacy for Th2-mediated allergic dermatitis, possibly due to the effects of the antihistamines on other cell types involved in skin inflammation [15].

The effects of orally administered olopatadine hydrochloride (olopatadine) on itching, itching mediators, and neuritogenic action was investigated in a mouse model. Olopatadine is a selective histamine $\mathrm{H}_{1}$-receptor antagonist possessing inhibitory effects on the release of inflammatory lipid mediators such as leukotriene and thromboxane from human polymorphonuclear leukocytes and eosinophils. Olopatadine was highly and rapidly absorbed. Olopatadine was one of the few renal clearance drugs in antiallergic drugs. This study confirmed the inhibition of inflammation and neurite extension into the epidermis [16].

Besides, the anti-allergic properties of olopatadine, it stabilizes mast cells by inhibiting the release of chemokines. Employing the standard patch-clamp whole-cell recording technique, Baba A et al., examined the effects of olopatadine and other anti-allergic drugs on the membrane Capacitance $(\mathrm{Cm})$ in rat peritoneal mast cells during exocytosis. Using confocal imaging of a water-soluble fluorescent dye, lucifer yellow, the authors also examined their effects on the deformation of the plasma membrane. Low concentrations of olopatadine $(1$ or $10 \mu \mathrm{M})$ did not significantly affect the increase in the $\mathrm{Cm}$. However, $100 \mu \mathrm{M}$ and $1 \mathrm{mM}$ olopatadine almost totally suppressed the increase in the $\mathrm{Cm}$. Besides, these doses completely washed out the trapping of the dye on the cell surface. The result indicated that olopatadine counteracted the membrane surface deformation induced by exocytosis. As shown by electron microscopy, olopatadine generated inward membrane bending in mast cells, the olopatadine. The study provided electrophysiological evidence for the first time that olopatadine dose-dependently inhibited the process of exocytosis in rat peritoneal mast cells. Such mast cell stabilizing properties of olopatadine might be attributed to its counteracting effects on the plasma membrane deformation in degranulating mast cells [17].

In order to increase the anti-inflammatory activity of antagonists of the histamine type 1 and 2 receptors $\left(\mathrm{H}_{1} / 2 \mathrm{r}\right)$ the topical usage was examined in a mouse model. Topical $\mathrm{H}_{1} / 2 \mathrm{r}$ antagonists enhanced permeability barrier homeostasis in normal mouse skin by the following mechanisms: (i) stimulation of epidermal differentiation, leading to thickened cornified envelopes; and (ii) enhanced epidermal lipid synthesis and secretion. The results obtained by Lin TK et al., could shift current paradigms of antihistamine utilization from a predominantly systemic to a topical approach [18].

The role of histamine $\mathrm{H}(4)$ receptor $(\mathrm{H}(4) \mathrm{R})$ was investigated in a T-helper type 2 (Th2)-cell-mediated mouse skin inflammation model. The effect of $\mathrm{H}(4) \mathrm{R}$ antagonism on dendritic cell migration in vivo may be an indirect result of the reduction in tissue cytokines and chemokines or a direct effect on chemotaxis. The significant inhibition of pruritus was shown in the mouse model as well [19].

The results obtained in a hapten-induced experimental model indicated that treatment with a $\mathrm{H}(4)$ receptor antagonist might be effective for amelioration of both skin inflammation and pruritus [20].

The opposite point of view was also presented. Kamo A et al., examined the therapeutic effects of $\mathrm{H}_{4} \mathrm{R}$ antagonists on itch and skin inflammation using a mouse model of AD. Dermatitis was induced by application of the ointment containing Dermatophagoides farina body. Mice were treated by either intraperitoneal injection with a vehicle (20\% dimethylsulphoxide and $80 \%$ 2-hydroxypropyl- $\beta$-cyclodextrin in saline) or $\mathrm{H}_{4} \mathrm{R}$ antagonists ( 10 or $30 \mathrm{mg} \mathrm{kg}^{-1}$ ) three times per week for 3 weeks. Kamo A et al., found that treatment with $\mathrm{H}_{4} \mathrm{R}$ antagonist (JNJ7777120 or JNJ28307474) provided no significant inhibition of scratching behavior or amelioration of dermatitis in mice [21]. This result was consistent with a recent study in a canine model of AD induced by Dermatophagoides farina house dust mites [22]. Meanwhile, another study using a model of allergic dermatitis reported that $\mathrm{H}_{4} \mathrm{R}$ antagonist JNJ7777120, but not $\mathrm{H}_{1} \mathrm{R}$ antagonists, showed both anti-inflammatory and anti-pruritic effects in fluorescein-5-isothiocyanate-induced dermatitis mouse model [23]. The recent study showed that $\mathrm{H}_{1} \mathrm{R}$ antagonist olopatadine and $\mathrm{H}_{4} \mathrm{R}$ antagonist JNJ7777120 improved scratching behavior and skin inflammation in a model of allergic dermatitis induced by repeated challenges with picryl chloride on the dorsal back of experimental mice (Ohsawa and Hirasawa) concluded that histamine $\mathrm{H}(4)$ receptor antagonists ineffective against itch and skin inflammation in atopic dermatitis mouse model [24].

\section{Antihistamines in Atopic Dermatitis}

The antihistamines are often prescribed for atopic dermatitis [25]. At the same time, the Cochrane review of studies that assessed the effects of oral $\mathrm{H}_{1}$ antihistamines as 'add-on' therapy together with concomitant treatments was warranted to determine the beneficial effects of this group of medications in the treatment. The potential benefits of oral $\mathrm{H}_{1}$ antihistamines were not proved [26]. On the other hand, Yamanaka et al., supports the view that $\mathrm{H}_{1}$-antihistamines may be effective in relieving the itch associated with $\mathrm{AD}$ [27]. 
Practically, the simultaneous usage of antihistamines and topical corticosteroids is appreciated $[9,28]$. The oral $\mathrm{H}_{1}$ antihistamines are used in severe cases of atopic dermatitis as well as corticotherapy, antibiotherapy, UVB $311 \mathrm{~nm}$, topical glucocorticoids and hydration [29].

The decrease of inflammation and enhanced barrier function which were demonstrated in a mouse model [16], appeared to be clinically effective as well. The topical use of promethasine, widely used for moderate acute and chronic itching conditions, is one of several strategies used to improve the tolerability profile of promethasine particularly with regard to gastric and renal adverse effects. The apparent ability of topical $\mathrm{H}_{1} \mathrm{r} / 2 \mathrm{r}$ antagonists to target epidermal $\mathrm{H}_{1} / 2 \mathrm{r}$ was translated into increased efficacy in the treatment of inflammatory dermatoses, likely due to decreased inflammation and enhanced barrier function. Topical promethasine has often been implicated in photosensitivity reactions. The higher frequency of such adverse reactions could be accounted for by its chemical structure and the variety of chemical reactions that give rise to the phototoxic effects. Promethasine allergy encompasses a spectrum of immunologically mediated hypersensitivity reactions with varying mechanisms and clinical presentations. The type of Adverse Drug Reaction (ADR) not only affects patient's quality of life, but may also lead to delayed treatment, unnecessary investigations, and even mortality. The most effective strategy for the management of drug allergy is avoidance or discontinuation of the offending drug and avoidance of sun exposure. When available, alternative medications with unrelated chemical structures should be substituted. Cross-reactivity among drugs should be taken into consideration when choosing alternative agents. Additional therapy for drug hypersensitivity reactions is largely supportive and may include topical corticosteroids, topical zinc oxide in severe cases, and systemic corticosteroids. In the event of anaphylaxis, the treatment of choice is injectable epinephrine. Promethazine ARs are classified as either predictable reactions that may occur in anyone or unpredictable reactions that occur in only susceptible individuals. Predictable reactions are the most common type of $\mathrm{ADR}$ and are usually dose dependent and related to the known pharmacologic actions of the drug (e.g., side effects, overdose, and drug interactions). Unpredictable reactions occur in approximately $20-25 \%$ of patients who experience ADRs; these reactions are generally unrelated to the pharmacologic actions of the drug [30].

The mechanisms responsible for the anti-inflammatory activity of $\mathrm{H}_{1}$-antihistamines are still unclear, but are presumed to be both receptor-dependent and receptor-independent. The anti-inflammatory effects improve the results of therapy in atopic dermatitis. First-generation $\mathrm{H}(1)$-antihistamines, all of which are sedating, are generally regarded as safe by laypersons and healthcare professionals because of their long-standing use. However, they reduce Rapid Eye Movement (REM)-sleep, impair learning and reduce work efficiency. They are implicated in civil aviation, motor vehicle and boating accidents, deaths as a result of accidental or intentional overdosing in infants and young children and suicide in teenagers and adults. $\mathrm{H}_{1}$-antihistamines may exhibit cardiotoxicity in overdose [31].

The second-generation antihistamines, being more lipophobic, offer the advantages of a lack of the central nervous system and cholinergic effects such as sedation and dry mouth, which are commonly seen in first-generation antihistamines. The longer duration of the second-generation antihistamines action also enables a more patient-friendly dosing regimen which increases patient compliance. Poluzzi E et al., identified signals of antihistamine arrhythmogenic potential by analyzing FAERS database for all cases of Torsades de pointes, QT abnormalities, ventricular arrhythmia and sudden cardiac death/cardiac arrest. It was proved that the second-generation antihistamines may be associated with signal of torsadogenicity [32].

New H (1)-antihistamines introduced for clinical use include oral formulations (bilastine and rupatadine), and ophthalmic formulations (alcaftadine and bepotastine). Clinical studies of $\mathrm{H}(3)$-antihistamines with enhanced decongestant effects have been conducted in patients with allergic rhinitis. Additional novel compounds being studied include $\mathrm{H}(4)$-antihistamines with anti-inflammatory effects in allergic rhinitis, atopic dermatitis, and other diseases [33,34].

Many examinations of different antihistamines were performed. Oral bepotastine is a second-generation histamine $\mathrm{H}$ (1) receptor antagonist. Bepotastine suppresses some allergic inflammatory processes. Various short- and long-term clinical trials and surveillance studies have shown that twice-daily bepotastine was an effective and generally well tolerated antihistamine in the treatment of patients with allergic rhinitis, chronic urticaria or pruritus associated with skin conditions (eczema/dermatitis, prurigo or pruritus cutaneus). Bepotastine $20 \mathrm{mg} /$ day was significantly more effective than terfenadine $120 \mathrm{mg} /$ day in patients with perennial allergic rhinitis, as evaluated by the final global improvement rating and several other endpoints in a phase III trial. In phase III trials in cases of chronic urticaria, bepotastine $20 \mathrm{mg}$ /day was more effective than placebo in improving levels of itching and eruption, and as effective as terfenadine $120 \mathrm{mg} /$ day with regard to the final global improvement rating and other endpoints. In a non-comparative trial in patients with pruritus associated with skin diseases, the majority of bepotastine recipients in the overall population, as well as in the specific skin disease subgroups (eczema/dermatitis, prurigo or pruritus cutaneus), had a final global improvement rating of moderate or greater. Bepotastine was generally well tolerated in adult and children with allergic conditions [35- 37].

It is known that second-generation antihistamines are less sedative or non-sedative drugs compared with the first generation, and the drugs have additional efficacy in blocking some chemical mediators [38]. A double-blind, placebo controlled, crossover study was done to concurrently compare the clinical effectiveness of promethazine, a first-generation antihistamine, and fexofenadine and olopatadine, second-generation antihistamines, by measuring their potency as peripheral inhibitors of histamine-induced wheal and flare. Fexofenadine and olopatadine had no significant effect in any of the psychomotor tests. Promethazine, fexofenadine and olopatadine did not affect behavioral activity, as measured by wrist actigraphy. These results suggest that olopatadine at a therapeutic dose has greater antihistaminergic activity than promethazine, and olopatadine and fexofenadine did not cause cognitive or psychomotor impairment [39].

In spite of the fact that second-generation antihistamines have fewer sedative effects than the first-generation antihistamines, important inter-drug differences remain in the degree of cognitive and/or psychomotor impairment. Isomura $\mathrm{T}$ et al., calculated the Proportional Impairment Ratio with 95\% confidence intervals as an index of reliability- and compare antihistamines currently with respect to their intrinsic capacity to cause impairment. Results from studies of 
cetirizine, desloratadine, ebastine, fexofenadine, levocetirizine, loratadine, mequitazine, and olopatadine were included in the calculations. Only fexofenadine (Proportional Impairment Ratio $=0.49$ ) had an upper limit of the $95 \%$ confidence intervals of less than 1. Fexofenadine, Levocetirizine, Desloratadine, Olopatadine, Loratadine, and Mequitazine all had a Proportional Impairment Ratio for subjective ratings of 0 , but the upper limits of the $95 \%$ confidence intervals.The results showed that there were differences between antihistamine in the extent of sedation produced [40].

A novel vesicular, dermally safe, and nontoxic topical formulation of cetirizine has been successfully developed and may be used to treat atopic dermatitis after clinical investigation [41-43].

The Substance P (SP) has been demonstrated to be one of the important neuropeptides for mediating itch-scratch and stress-scratch cycles. Hosokawa $\mathrm{C}$ et al., examined the severity scores, itch scores and plasma SP levels in 19 patients with AD treated with standard topical therapy with or without an oral antihistamine, olopatadine hydrochloride, for 4 weeks. The standard therapy decreased SCORAD scores, itch behavioral rating scores and plasma SP levels at post-treatment in the mass. The topical therapy with olopatadine was more effective than the topical therapy alone, suggesting a potential additive effect [44].

Ohsawa $\mathrm{Y}$ and Hirasawa $\mathrm{N}$, evaluated the oral administration of $\mathrm{H}_{1} \mathrm{R}$ antagonists as not very effective. They supposed that the next generation antihistaminic agents possessing $\mathrm{H}_{1} \mathrm{R}$ and $\mathrm{H}_{4} \mathrm{R}$ antagonistic actions would be a potent therapeutic drug for $\mathrm{AD}$ [45]. The results of investigation performed by Suwa E et al., investigated the expression of $\mathrm{H}_{4}$ receptor mRNA and the function of the receptor in a culture system that mimics in vivo inflammation on the human keratinocyte cell line (HaCaT cells). Increased expression of the $\mathrm{H}_{4}$ receptor was observed in $\mathrm{HaCaT}$ cells following differentiation. Treatment of HaCaT cells with histamine and TNFa enhanced the mRNA expression of Interleukin (IL)-8. These increases in expression were significantly inhibited by the $\mathrm{H}_{4}$ receptor antagonist JNJ7777120. The results indicated that IL- 8 mRNA expression might be enhanced by histamine and TNFa via $\mathrm{H}_{4}$ receptor stimulation in keratinocytes [46]. The introduction of the reference $\mathrm{H}_{4} \mathrm{R}$ antagonist JNJ-7777120 (Johnson \& Johnson Pharmaceutical Research \& Development LLC/Abbott Laboratories), and proof of the efficacy of this agent in models of asthma, allergic rhinitis and pruritus, highlighted the $\mathrm{H}_{4} \mathrm{R}$ as a novel drug target [47].

\section{The Disproof of Antihistamines Therapy in Atopic Dermatitis}

The patients with moderate to severe $\mathrm{AD}$ may be unresponsive to antihistamines [48]. Besides, some investigations demonstrated the senseless of antihistamine usage. The Course of Advanced Learning for the Management of ITch (CALM-IT) Task Force is an interdisciplinary group of experts specializing in core aspects of pruritus treatment, integrating pediatrics, dermatology, psychotherapy, pruritus management, and sleep. CALM-IT recently convened to provide updated guidance on managing chronic pruritus associated with dermatologic diseases in pediatric patients, with a special focus on Atopic Dermatitis (AD) and chronic spontaneous Urticaria (csU). Metz $\mathrm{M}$ et al., emphasized that the new experimental findings do not support the use of non-sedating oral antihistamines as adjuvant antipruritic therapy for $\mathrm{AD}$ [49].
Yarbrough KB et al., emphasized that the most effective treatments for atopic dermatitis-associated itch were primarily topical or systemic anti-inflammatory agents [50].

According to Lyons JJ et al., antihistamines have demonstrated poor efficacy in controlling $\mathrm{AD}$-associated itch [51].

\section{Conclusion}

The antihistamines are commonly used to treat AD. These dating type of antihistamines have long been prescribed in $\mathrm{AD}$ in order to reduce pruritus. The anti-inflammatory effect of antihistamines is described. The practical feasibility of antihistamines was proved many times. Further works on new formula of antihistamine are being continued. For example, novel vesicular, dermally safe, and nontoxic topical formulation of cetirizine is being examined. The next generation of antihistaminic agents possessing $\mathrm{H}_{1} \mathrm{R}$ and $\mathrm{H}_{4} \mathrm{R}$ antagonistic actions encourage also.

The various side effects are described in antihistamines therapy, but the fact does not diminish the practical usage of antihistamines.

Far less investigators support another point of view according to which, there is no reliable high-level evidence to support or refute the efficacy or safety of oral $\mathrm{H}_{1}$ antihistamines used as monotherapy. Some authors deny the efficacy of antihistamines in atopic dermatitis. Of course, fewer opinions are not surely wrong opinions. We can propose some limitations for prescription of antihistamines in future and further investigations in the field seem to be needed.

\section{References}

1. Ständer S, Luger TA (2010) Itch in atopic dermatitis - pathophysiology and treatment. Acta Dermatovenerol Croat 18: 289-296.

2. Buddenkotte J, Steinhoff M (2010) Pathophysiology and therapy of pruritus in allergic and atopic diseases. Allergy 65: 805-821.

3. Metz M, Ständer S (2010) Chronic pruritus--pathogenesis, clinical aspects and treatment. J Eur Acad Dermatol Venereol 24: 1249-1260.

4. Grundmann S, Ständer S (2011) Chronic pruritus: clinics and treatment. Ann Dermatol 23: 1-11.

5. Raap U, Ständer S, Metz M (2011) Pathophysiology of itch and new treatments. Curr Opin Allergy Clin Immunol 11: 420-427.

6. Ständer S, Raap U, Weisshaar E, Schmelz M, Mettang T, et al. (2011) Pathogenesis of pruritus. J Dtsch Dermatol Ges 9: 456-463.

7. Akiyama T, Tominaga M, Takamori K, Carstens MI, Carstens E (2014) Roles of glutamate, substance $P$, and gastrin-releasing peptide as spinal neurotransmitters of histaminergic and nonhistaminergic itch. Pain 155: 80-92.

8. Rossbach K, Nassenstein C, Gschwandtner M, Schnell D, Sander K, et al. (2011) Histamine $\mathrm{H}_{1}, \mathrm{H}_{3}$ and $\mathrm{H}_{4}$ receptors are involved in pruritus. Neuroscience 190: 89-102.

9. Werfel T, Claes C, Kulp W, Greiner W, von der Schulenburg JM (2006) Therapy of atopic eczema. GMS Health Technol Assess 2: Doc19.

10. Eichenfield LF, Tom WL, Berger TG, Krol A, Paller AS, et al. (2014) Guidelines of care for the management of atopic dermatitis: section 2. Management and treatment of atopic dermatitis with topical therapies. J Am Acad Dermatol 71: 116- 132.

11. Sidbury R, Davis DM, Cohen DE, Cordoro KM, Berger TG, et al. (2014) Guidelines of care for the management of atopic dermatitis: section 3. Management and treatment with phototherapy and systemic agents. J Am Acad Dermatol 71: 327-349.

12. Church MK, Maurer $M(2015) H_{1}$-Antihistamines and itch in atopic dermatitis. Exp Dermatol. 
13. Apfelbacher CJ, van Zuuren EJ, Fedorowicz Z, Jupiter A, Matterne U, et al (2013) Oral $\mathrm{H}_{1}$ antihistamines as monotherapy for eczema. Cochrane Database Syst Rev 2: CD007770.

14. Nakasone T, Sato T, Matsushima Y, Inoue T, Kamei C (2015) Characteristics of scratching behavior in ADJM mice (Atopic Dermatitis from Japanese Mice). Immunopharmacol Immunotoxicol 37: 202-206.

15. Schumacher S, Kietzmann M, Stark H, Bäumer W (2014) Unique immunomodulatory effects of azelastine on dendritic cells in vitro. Naunyn Schmiedebergs Arch Pharmacol 387: 1091-1099.

16. Murota H, El-latif MA, Tamura T, Amano T, Katayama I (2010) Olopatadine hydrochloride improves dermatitis score and inhibits scratch behavior in $\mathrm{NC} /$ Nga mice. Int Arch Allergy Immunol 153: 121-132.

17. Baba A, Tachi M, Maruyama Y, Kazama I (2015) Olopatadine inhibits exocytosis in rat peritoneal mast cells by counteracting membrane surface deformation. Cell Physiol Biochem 35: 386-396.

18. Lin TK, Man MQ, Santiago JL, Park K, Roelandt T, et al. (2013) Topical antihistamines display potent anti-inflammatory activity linked in part to enhanced permeability barrier function. J Invest Dermatol 133: 469- 478

19. Cowden JM, Zhang M, Dunford PJ, Thurmond RL (2010) The histamine $H_{4}$ receptor mediates inflammation and pruritus in Th2-dependent dermal inflammation. J Invest Dermatol 130: 1023-1033.

20. Suwa E, Yamaura K, Oda M, Namiki T, Ueno K (2011) Histamine H(4) receptor antagonist reduces dermal inflammation and pruritus in a hapten-induced experimental model. Eur J Pharmacol 667: 383-388.

21. Kamo A, Negi O, Tengara S, Kamata Y, Noguchi A, et al. (2014) Histamine $\mathrm{H}(4)$ receptor antagonists ineffective against itch and skin inflammation in atopic dermatitis mouse model. J Invest Dermatol 134: 546-548.

22. Bäumer W, Stahl J, Sander K, Petersen LJ, Paps J, et al. (2011) Lack of preventing effect of systemically and topically administered histamine $\mathrm{H}(1)$ or $\mathrm{H}(4)$ receptor antagonists in a dog model of acute atopic dermatitis. Exp Dermatol 20: 577- 581

23. Cowden JM, Zhang M, Dunford PJ, Thurmond RL (2010) The histamine $\mathrm{H}_{4}$ receptor mediates inflammation and pruritus in Th2-dependent dermal inflammation. J Invest Dermatol 130: 1023-1033.

24. Ohsawa $\mathrm{Y}$, Hirasawa N (2012) The antagonism of histamine $\mathrm{H}_{1}$ and $\mathrm{H}_{4}$ receptors ameliorates chronic allergic dermatitis via anti-pruritic and anti-inflammatory effects in NC/Nga mice. Allergy 67: 1014-1022.

25. Chrostowska-Plak D, Salomon J, Reich A, Szepietowski JC (2009) Clinical aspects of itch in adult atopic dermatitis patients. Acta Derm Venereol 89 : 379-383

26. van Zuuren EJ, Apfelbacher CJ, Fedorowicz Z, Jupiter A, Matterne U, et al (2014) No high level evidence to support the use of oral $\mathrm{H}_{1}$ antihistamines as monotherapy for eczema: a summary of a Cochrane systematic review. Syst Rev 3: 25.

27. Yamanaka K, Motomura E, Noro Y, Umeda K, Morikawa T, et al. (2015) Olopatadine, a non sedating $\mathrm{H}_{1}$ antihistamnine, decreases the nocturnal scratching without affecting sleep quality in atopic dermatitis. ExpDermatol 24: $227-229$

28. Khamaganova I (2012) Alleviation of a severe pruritic flare-up in a 13-yearold child with chronic atopic dermatitis treated with methylprednisolone aceponate $0.1 \%$. J Eur Acad Dermatol Venereol 26: 20-21.

29. Lancrajan C, Bumbacea R, Giurcaneanu C (2010) Erythrodermic atopic dermatitis with late onset--case presentation. J Med Life 3: 80-83.

30. Cantisani C, Ricci S, Grieco T, Paolino G, Faina V, et al. (2013) Topical promethazine side effects: our experience and review of the literature. Biomed Res Int 2013: 151509.

31. Church MK, Maurer M, Simons FE, Bindslev-Jensen $C$, van Cauwenberge $P$ et al. (2010) Risk of first-generation $\mathrm{H}(1)$-antihistamines: a GA(2)LEN position paper. Allergy 65: 459-466.
32. Poluzzi E, Raschi E, Godman B, Koci A, Moretti U, et al. (2015) Pro-Arrhythmic Potential of Oral Antihistamines $\left(\mathrm{H}_{1}\right)$ : Combining Adverse Event Reports with Drug Utilization Data across Europe. PLoS One 10: 0119551.

33. Vena GA, Cassano N, Buquicchio R, Ventura MT (2008) Antiinflammatory effects of $\mathrm{H}_{1}$-antihistamines: clinical and immunological relevance. Curr Pharm Des 14: 2902-2911.

34. Simons FE, Simons KJ (2011) Histamine and $\mathrm{H}_{1}$-antihistamines: celebrating a century of progress. J Allergy Clin Immunol 128: 1139-1150.

35. Lyseng-Williamson KA (2010) Oral bepotastine: in allergic disorders. Drugs 70: 1579-1591

36. Kawakami T, Kimura S, Haga T, Doi R, Kyoya M, et al. (2012) Health-related quality of life assessed by the effect of bepotastine besilate in patients with pruritus: importance of emotions score in atopic dermatitis. J Dermatol 39: 527-530.

37. Bielory L, Duttachoudhury S, McMunn A (2013) Bepotastine besilate for the treatment of pruritus. Expert Opin Pharmacother 14: 2553-2569.

38. Yamashita H, Tanaka H, Inagaki N (2013) Treatment of the chronic itch of atopic dermatitis using standard drugs and kampo medicines. Biol Pharm Bull 36: 1253-1257.

39. Kamei H, Isaji A, Noda Y, Ishikawa K, Senzaki K, et al. (2012) Effects of single therapeutic doses of promethazine, fexofenadine and olopatadine on psychomotor function and histamine-induced wheal- and flare-responses: a randomized double-blind, placebo-controlled study in healthy volunteers. Arch Dermatol Res 304: 263-272.

40. Isomura T, Kono T, Hindmarch I, Kikuchi N, Murakami A, et al. (2014) Central nervous system effects of the second-generation antihistamines marketed in japan -review of inter-drug differences using the Proportional Impairment Ratio (PIR)-. PLoS One 9: 114336.

41. Goindi S, Kumar G, Kumar N, Kaur A (2013) Development of novel elastic vesicle-based topical formulation of cetirizine dihydrochloride for treatment of atopic dermatitis. AAPS PharmSciTech 14: 1284- 1293.

42. Goindi S, Dhatt B, Kaur A (2014) Ethosomes-based topical delivery system of antihistaminic drug for treatment of skin allergies. J Microencapsul 31: 716724.

43. Goindi S, Kumar G, Kaur A (2014) Novel flexible vesicles based topical formulation of levocetirizine: in vivo evaluation using oxazolone-induced atopic dermatitis in murine model. J Liposome Res 24: 249-257.

44. Hosokawa C, Takeuchi S, Furue M (2009) Severity scores, itch scores and plasma substance $P$ levels in atopic dermatitis treated with standard topical therapy with oral olopatadine hydrochloride. J Dermatol 36: 185-190.

45. Ohsawa $\mathrm{Y}$, Hirasawa $\mathrm{N}$ (2014) The role of histamine $\mathrm{H}_{1}$ and $\mathrm{H}_{4}$ receptors in atopic dermatitis: from basic research to clinical study. Allergol Int 63: 533542

46. Suwa E, Yamaura K, Sato S, Ueno K (2014) Increased expression of the histamine $\mathrm{H}_{4}$ receptor following differentiation and mediation of the $\mathrm{H}_{4}$ receptor on interleukin-8 mRNA expression in HaCaT keratinocytes. Exp Dermato 23: $138-140$.

47. Engelhardt H, Smits RA, Leurs R, Haaksma E, de Esch IJ (2009) A new generation of anti-histamines: Histamine $\mathrm{H}_{4}$ receptor antagonists on their way to the clinic. Curr Opin Drug Discov Devel 12: 628-643.

48. Lyakhovitsky A, Barzilai A, Heyman R, Baum S, Amichai B, et al. (2010) Low-dose methotrexate treatment for moderate-to-severe atopic dermatitis in adults. J Eur Acad Dermatol Venereol 24: 43-49.

49. Metz M, Wahn U, Gieler U, Stock P, Schmitt J, et al. (2013) Chronic pruritus associated with dermatologic disease in infancy and childhood: update from an interdisciplinary group of dermatologists and pediatricians. Pediatr Allergy Immunol 24: 527-539.

50. Yarbrough KB, Neuhaus KJ, Simpson EL (2013) The effects of treatment on itch in atopic dermatitis. Dermatol Ther 26: 110-119.

51. Lyons JJ, Milner JD, Stone KD (2015) Atopic dermatitis in children: clinical features, pathophysiology, and treatment. Immunol Allergy Clin North Am 35: 161-183. 